EQUAL REPRESENTATION IN TWO-TIER VOTING SYSTEMS

\author{
Nicola Maaser and Stefan Napel \\ CSGR Working Paper Number 185/05
}

December 2005 


\title{
Equal Representation in Two-tier Voting Systems*
}

Nicola Maaser and Stefan Napel

CSGR Working Paper Number 185/05

December 2005

\begin{abstract}
:
The paper investigates how voting weights should be assigned to differently sized constituencies of an assembly. The one-person, one-vote prin ciple is interpreted as calling for a priori equal indirect influence on decisions. The latter are elements of a one-dimen sional convex policy space and may result from strategic behavior consistent with the median voter theorem. Numerous artificial constituency configurations, the EU and the US are investigated by Monte-Carlo simulations. Penrose's square root rule, which oniginally applies to preferencefree dichotomous decision environments and holds only under very specific conditions, comes close to ensuring equal representation. It is thus more robust than previously su ggested.
\end{abstract}

Keywords: equal representation, one person one vote, voting systems, voting power

\section{Contact Details:}

\author{
Nicola Maaser \\ University of Hamburg \\ Department of Economics \\ Von-Melle-Park 5 \\ D-20146 Hamburg \\ nicolamaaser@yahoo.de
}

\author{
Stefan Napel ${ }^{* *}$ \\ University of Hamburg \\ Department of Economics \\ Von-Melle-Park 5 \\ D-20146 Hamburg \\ napel@econ.uni-hamburg.de
}

\footnotetext{
${ }^{*}$ We thank M. Braham, M. J. Holler, and participants of the workshop Voting Power \& Procedures, Warwick, 2005 , for their constructive comments.

${ }^{* *}$ Corresponding author.
} 


\section{Introduction}

The principle of "one person, one vote" is generally taken to be a cornerstone of democracy. It is not clear, however, how this principle ought to be operationalized in practice either in terms of apportioning an integer number of seats for given non-integer 'ideal shares' (see Balinski and Young 2001) or in determining what are the ideal shares. This paper addresses the latter problem for two-tier voting systems that involve multiple constituencies ofdifferent population size. We concentrate on situations in which representatives of constituencies in the higher-level assembly vote as a block (as in the US Electoral College) or in which a single agent represents each constituency but is endowed with a number of votes that somehow reflect population size (as in the EU Council of Ministers). Both boil down to weighted voting.

Although it seems straightforward to allocate weights proportional to population sizes, this ignores the combinatorial properties of weighted voting, which often imply stark discrepancies between voting weight and actual voting power. In an assembly with simple majority rule and three representatives having weight 47,43 , and 10 , all three possess exactly the same number of possibilities to form a winning coalition and hence the same a priori power. Moreover, direct proportionality disregards the possibly nonlinear relationship between population size and an individual's effect on the respective constituency's top-tier policy position.

The most well-known solution to this problem is the one first suggested by Penrose (1946). Starting from the ideal world in which only constituency membership ${ }^{1}$ distinguishes voters, Penrose found that if members of any constituency are to have the same a priori chance to ind irectly determine the outcome of top-tier decisions, then constituencies' voting weights need to be such that their power at the top-tier as measured by the Penrose-Banzhaf index (Penrose 1946; Banzhaf 1965) is proportional to the square root of the respective constituency's population size (also see Felsenthal and Machover 1998, sect. 3.4). This square root rule has recently become the benchmark for numerous studies of the EU Council of Ministers (see, e.g. Felsenthal and Machover 2001, 2004, Leech 2002) and it is at least a reference point for investig ations concerning the US (see e.g. Gelman, Katz and Bafumi 2004).

Applying the square root rule has, unfortunately, two weaknesses: First, Penrose's theorem critically depends on equiprobable 'yes' and 'no'-decisions by all voters (or at least a 'yes'-

\footnotetext{
${ }^{1}$ We take the constituency configuration to be given exogenously. See, e.g., Epstein and O'Halloran (1999) on constructing majority-minority voting districts along ethnic, religious, or social lines.
} 
probability which is random and distributed independently across voters with mean exactly 0.5 ). If the 'yes'-probability is slightly lower or higher, or if it exhibits even minor dependence across voters - say, they are influenced by the same newspapers - then the square root rule may result in highly unequal representation (see Good and Mayer 1975 and Chamberlain and Roth schild 1981). Related empirical studies in fact have failed to confirm the predictions for average closeness of two-party elections which lie behind the square root rule (see Gelman, Katz, and Tuerlinckx 2002 and Gelman, Katz, and Bafumi 2004).

Second, rigorous justifications for using the square root rule as the benchmark have so far concerned only preference-free binary voting. ${ }^{2}$ But real decisions are rarely binary, e.g., about either introducing a tax, building a road, accepting a candidate, introducing affirmative action, etc. or not. At least at intermediate levels there is a preference-driven compromise that involves many alternative tax levels, road attributes, suitable candidates, degrees of affirmative action, etc.

The first criticism has been addressed in the literature, at least in abstract normative terms. Namely, one can argue that constitutional design should to be carried out behind a thick veil of ignorance in which no particular type of dependence or modification of equiprobability (which follows from the principle of insufficient reason) is justified. Regarding the second issue, this paper is to our knowledge the first to investigate equal representation for non-binary decisions that possibly involve strategic behavior.

We consider policy alternatives from a one-dimensional convex space. ${ }^{3}$ Our formal model (see Section 2) imposes two key assumptions: first, the policy advocated by the top-tier representative of any given constituency coincides with the ideal point of the respective constituency's median voter (or the constituency's core). Second, the decision taken at the top tier is the position of the pivotal representative (or the assembly's core), with pivotality determined by the weights assigned to constituencies and a 50\% decision quota. The respective core is meant to capture the result of strategic interaction. As long as this is a reasonable approximation, the actual systems determining collective choices are undetermined and could even differ

\footnotetext{
${ }^{2}$ For rigorous, very comprehensive treatments of the binary or simple-game world see Felsenthal and Machover (1998) or Taylor and Zwicker (1999). - The former (pp. 72ff) also justify the square root rule regarding voting weights by its minimal expected majority deficit. Feix, Lepelley, Merlin, Rouet, and Vidu (2005) report related results for the probability of the referendum paradox.

${ }^{3}$ One could alternatively consider aggregate decisions that divide a 'pie', e.g., the distribution of public expenditures. This has been pursued empirically, for example, by Ansolabehere, Gerber, and Snyder (2002) and Horiuchi and Saito (2003).
} 
across constituencies.

In the benchmark case of voters with independent most-preferred policies, a given individual's chance to be pivotal at the bottom tier is inversely proportional to the respective constituency's population size. This makes it necessary and sufficient for equal representation of voters that the probability of any given constituency being pivotal at the top tier is proportional to its size. $^{4}$

The population size of a constituency affects the distribution of its median. A given voter's chance to be doubly pivotal thus becomes a rather complex function of (the order statistics of) differently distributed independent random variables. This makes a neat analytical statement similar to Penrose's rule exceptionally hard and likely impossible, except for special limit situ ations. We therefore resort to Monte-Carlo simulation (see Section 3). Considering a vast number of randomly generated population configurations as well as recent data for the EU and the US, top-tier weights proportional to the square root of population turn out optimal for most practically relevant population configurations. Even for exreme artificial cases, the rule yields good results and becomes optimal if the number of constituencies gets large.

Our surprising main finding is thus that the square root rule is a much more robust norm for egalitarian design of two-tier voting systems than previous analysis suggests. In particular, it continues to apply in the presence of many finely graded policy alternatives and strategic interactions consistent with the median voter theorem. To the extent that this still produces independent median voters, the rule is even robust to the introduction of preference dependence within or across constituencies.

\section{Model}

Consider a large population of voters partitioned into $m$ constituencies $C_{1}, \ldots, C_{m}$ with $n_{j}=\left|C_{j}\right|$

$>0$ members each. Voters' preferences are single-peaked with ideal point $\lambda_{i}^{j}$ (for $i=1, \ldots, n_{j}$ and $j=1, \ldots, m)$ in a convex one-dimensional policy space normalized to $X \equiv[0,1]$. Assume for simplicity that all $\mathrm{n}_{j}$ are odd numbers.

For any random policy issue, let $\cdot: n_{j}$ denote the permutation of voter numbers in constituency $C_{j}$ such that 


$$
\lambda_{1: n_{j}}^{j} \leq \ldots \leq \lambda_{n_{j}: n_{j}}^{j}
$$

holds. In other words, $k: n_{j}$ denotes the $k$-th leftmost voter in $C_{j}$ and $\lambda_{k: n_{j}}^{j}$ denotes the $k$-th leftmost ideal point (i.e., $\lambda_{k: n_{j}}^{j}$ is the $k$-th order statistic of $\lambda_{1}^{j}, \ldots, \lambda_{n_{j}}^{j}$ ).

A policy $x \in X$ is decided on by an electoral college $E$ consisting of one representative from each constituency. Without going into details, we assume that the representative of $C_{j}$, denoted by $j$, adopts the ideal point of his constituency's median voter, ${ }^{5}$ denoted by

$$
\lambda^{j}=\lambda_{\left(n_{j}+1\right) / 2: n_{j}}^{j} .
$$

Let $?^{k: m}$ denote the k-th leftmost ideal point amongst all the representatives (i. e., the $k$-th order statistic of $\left.?^{1}, \ldots, ?^{m}\right)$.

In the top-tier assembly or electoral college $E$, each constituency $C_{j}$ has voting weight $w_{j}$ $\geq 0$. Any subset $S \subseteq\{1, \ldots, m\}$ of representatives which achieves a combined weight $\sum_{j \in S} w_{j}$ above $q \equiv 1 / 2 \sum_{j=1}^{m} w_{j}$, i.e. a simple majority of total weight, can implement a policy $x \in X$.

Consider the random variable $P$ defined by

$$
P \equiv \min \left\{r \in\{1, \ldots, m\}: \sum_{k=1}^{r} w_{k: m}>q\right\} .
$$

Player $P: m$ 's ideal point, $\lambda^{P: m}$, is the unique policy that beats any alternative $x \in X$ in a pairwise majority vote, i.e. constitutes the core of the voting game defined by weights and quota. ${ }^{6}$ Without detailed equilibrium analysis of any decision procedure that may be applied inE (see Banks and Duggan 2000 for sophisticated non-cooperative support of policy outcomes inside or close to the core), we assume that the policy agreed by $E$ is in the core, i.e. it equals the ideal point of the pivotal representative $P: m$.

\footnotetext{
'If voters' utility is linear in distance, the criterion also guarantees equal expected utility, i.e., a priori power and expected success are then perfectly aligned. See Laruelle, Martinez, and Valenciano (2006) for a conceptual discussion of the latter.

${ }^{5} \mathrm{We}$ are aware that this may not in all applied contexts be appropriate. - The possibility that two ideal points exactly coincide, in which case the median voter (in contrast to the median policy) is not weltdefined, is ignored. This is innocuous for any continuous ideal point distribution.

${ }^{6}$ Things are more complicated if $q>\sum_{j=1}^{m} w_{j}$, is assumed. Then, the complement of a losing coalition need no longer be winning. In this case there may not exist any policy $x \in X$ which beats all alternatives $x^{\prime} \neq x$ despite unidimensionality of $X$ and single-peakedness of preferences.
} 
In this setting we consider the following egalitarian norm: Each voter in any constituency should have an equal chance to determine the policy implemented by the electoral college. Or, more formally, there should exist a constant $c>0$ such that

$$
\forall j \in\{1, \ldots, m\}: \forall i \in C_{j}: \operatorname{Pr}\left(j=P: m, i=\left(n_{j}+1\right) / 2: n_{j}\right) \equiv c .
$$

We would like to answer the following question: which allocation of weights $w_{1}, \ldots, w_{m}$ satisfies this norm (at least approximately) for an arbitrary given partition of an electorate into $m$ constituencies? In other words we search for an analogue of Penrose's (1946) rule, which calls for proportionality of a constituency's Penrose-Banzhaf index ${ }^{7}$ and square root of population.

The probability of a voter's double pivotality in (1) depends on the distribution of all voters' ideal points. Though in practice ideal points in different constituencies may come from different distributions on $X$ and may exhibit various dependencies, it is appealing from a normative constitutional-design point of view to presume that the ideal points of all voters in all constituencies are independently and identically distributed (i.i.d.).

Given that voters' ideal points in constituency $C_{j}$ are i.i.d., each voter $i \in C_{j}$ has the same probability to be its median. Hence,

$$
\forall j \in\{1, \ldots, m\}: \forall i \in C_{j}: \operatorname{Pr}\left(i=\left(n_{j}+1\right) / 2: n_{j}\right)=1 n_{j} .
$$

Using that the events $\left\{i=\left(n_{j}+1\right) / 2: n_{j}\right\}$ and $\{j=P: m\}$ are independent, one can thus write (1) as

$$
\forall j \in\{1, \ldots, m\}: \frac{\operatorname{Pr}(j=P: m)}{n_{j}} \equiv c .
$$

So if constituency $C_{j}$ is twice as large as constituency $C_{k}$ representative $j$ must have twice the chances to be pivotal than representative $k$ in order to equalize individual voters' chances to be pivotal.

For illustration suppose that representatives' ideal points $\lambda^{l}, \ldots, \lambda^{m}$ are i.i. d. Then, $\operatorname{Pr}(j=P: m)$ is simply the Shapley -Shubik index $(\mathrm{SSI})$ value, $\phi_{j}(w, q)$, of representative $j$ in vo ting body $\mathrm{E}$ defined by weight vector $w=\left(w^{1}, \ldots, w^{\mathrm{m}}\right)$ and quota $q$ (see Shapley and Shubik 1954). Therefore, making the i.i.d. assumption at the level of representatives would imply a lin-

\footnotetext{
7This index equals a constituency's probability of being pivotal under equiprobable random 'yes'-or-'no' votes at the top tier. Conditions for when this is approximately the voting weight are given by Lindner and Machover (2004). In general, implementing Penrose's square root rule requires numerical solution of the inverse problem of finding weights which induce a desired power distribution (see Leech 2003).
} 
ear rule based on the SSI as the replacement for Penrose's square root rule. In other words, $w$ would have to be chosen such that $\phi_{f}(w, q)$ is directly proportional to population size $n_{j}$ for all constituencies $j=1, \ldots, m-$ a relatively simple task.

However, it is in our view more convincing in egalitarian analysis to assume i.i.d. ideal points at the level of individual voters. Then, representatives' ideal points $\lambda^{1}, \ldots, \lambda^{m}$ are independently but (except in the trivial case $n_{1}=\ldots=n_{m}$ ) not identically distributed. If all voter ideal points come from the (arbitrary) identical distribution $F$ with density $f$, then $C_{j}$ 's median position is asymptotically normally distributed (see e.g. Arnold, Balakrishnan, and Nagaraja 1992) with mean

$$
\mu^{j}=F^{-1}(0.5)
$$

and standard deviation

$$
\sigma^{j}=\frac{1}{2 f\left(F^{-1}(0.5)\right) \sqrt{n_{j}}} .
$$

So, the larger a constituency $C_{j}$ is, the more concentrated is the distribution of its median voter's ideal point, $\lambda^{j}$, on the median of the underlying ideal point distribution (assumed to be identical for all $\lambda_{i}^{j}$ ). This makes the representative of a larger constituency on average more central in the electoral college and more likely to be pivotal in it for a given weight allocation.

It is important to observe that the assumption of the respective collective preferences having an identical a priori distribution is inconsistent with the assumption that all individual preferences are a priori identically distributed. The ntuitively appealing linear rule of giving twice the weight (or SSI voting power) to a constituency double the size violates the one-person, onevote principle if one makes the latter assumption. We find it considerably more fitting and will assume i.i.d. ideal points for all bottom-tier voters throughout this paper. Weights and SSI of constituencies hence need to be increasing in population size but less than linearly.

Probability $\operatorname{Pr}(j=P: m)$ in (2) depends both on the different distributions of representatives' ideal points (essentially the standard deviations $\sigma^{j}$ determined by constituency sizes $n_{j}$ ) and the voting weight assignment. This makes computation of the probability of a given constituency $C_{j}$ being pivotal a complex numerical task even for the most simple case of uniform weights, in which the representative of $C_{j}$ with median top-tier ideal point is always pivotal, i.e. 
$P \equiv(m+1) / 2$ for odd $m$. Define $\mathrm{N}^{j} \equiv\{1, \ldots, j-1, j+1, \ldots, m\}$ as the index set of all constituencies except $C_{j}$. Then, the probability of constituency $C_{j}$ being pivotal is

$$
\begin{aligned}
\operatorname{Pr}(j=(m+1) / 2: m) & =\operatorname{Pr}\left(\operatorname{exactly} \frac{m-1}{2} \text { of the } \lambda^{k}, k \neq j, \text { satisfy } \lambda^{k}<\lambda^{j}\right) \\
& =\int \sum_{\substack{S \subset \mathrm{N}^{j} \\
|S|=(m-1) / 2}} \prod_{k \in S} F_{k}(x) \cdot \prod_{k \in \mathrm{N}^{j} \backslash S}\left(1-F_{k}(x)\right) \cdot f_{j}(x) d x
\end{aligned}
$$

where $f_{j}$ and $F_{j}$ denote the density and cumulative density functions of $\lambda^{j}(j=1, \ldots, m)$. It seems feasible (but is beyond the scope of this paper) to provide an asymptotic approximation for this probability as a function of constituency sizes $n_{1}, \ldots, n_{m}$ for special cases, e.g. for $n_{2}=\ldots=n_{m}$ (hence $F_{2}=\ldots=F_{m}$ ). However, we doubt the existence of a reasonable approximation for arbitrary configurations $\left(n_{1}, \ldots, n_{m}\right)$. Proceeding to the case of weighted voting

$(P \equiv(m+1) / 2)$, even success in more generally approximating

$$
\operatorname{Pr}(j=p: m)=\int \sum_{\substack{S \subset N^{j} \\|S|=p-1}} \prod_{k \in S} F_{k}(x) \cdot \prod_{k \in \mathbb{N}^{j} \mid S}\left(1-F_{k}(x)\right) \cdot f_{j}(x) d x
$$

for any given realization $p$ of random variable $P$ would be of little help because events $\{P=p\}$ and $\{j=p: m\}$ are no longer independent. ${ }^{8}$ So, typically,

$$
\operatorname{Pr}(j=P: m) \neq \sum_{p=1}^{m} \operatorname{Pr}(P=p) \cdot \operatorname{Pr}(j=p: m)
$$

A purely analytical investigation of the model is therefore unlikely to produce much insight. The following section for this reason uses Monte-Carlo simulation in order to approximate the probability of any constituency $C_{j}$ being pivotal for given partition of an electorate or config $u$ ration $\left\{C_{1}, \ldots, C_{m}\right\}$ and a fixed weight vector $\left(w_{1}, \ldots, w_{m}\right)$. Based on this, we try to find weights $\left(w_{1}^{*}, \ldots, w_{m}{ }^{*}\right)$ which approximately satisfy the two equivalent equal representation conditions (1) and (2).

\footnotetext{
${ }^{8}$ To see this, consider the artificial case of representative $j$ having weight $w_{j}>0.5$ even though all constituencies are of equal size, so that ideal points $\lambda^{k}(k=1, \ldots, m)$ are i.i.d. Since $j$ is a dictator, $\operatorname{Pr}(j=P: m)=1 . \operatorname{But} \operatorname{Pr}(P=p)$ $=1 / m$ and $\operatorname{Pr}(j=p: m)=1 / m$ for all $p$.
} 


\section{Simulation results}

The problem of finding probability $\pi_{j} \equiv \operatorname{Pr}(j=P: m)$ is similar to that of evaluating the odds of rolling a "6" with a funny -shaped dice: while one may conceivably solve a complex dynamic model with several partial differential equations, it is equally reliable to simply roll the dice many times and keep track of " 6 "s. In particular, $\pi_{j}$ can be viewed as the expected value of the random variable $H_{j} \equiv g_{j}{ }^{w}\left(\lambda^{1}, \ldots, \lambda^{\mathrm{m}}\right)$ which equals 1 if $j=P: m$ holds for given weight vector $w$ and realized median ideal points $\lambda^{1}, \ldots, \lambda^{\mathrm{m}}$, and 0 otherwise. The Monte-Carlo method (Metropolis and Ulam 1949) then exploits that the empirical average of $s$ independent draws of $H_{j}$,

$$
\bar{h}_{j}^{s}=\frac{1}{s} \sum_{l=1}^{s} h_{j}^{l},
$$

converges to $H_{j}$ 's theoretical expectation

$$
\mathrm{E}\left(H_{j}\right)=\pi_{j}
$$

by the law of large numbers. The speed of convergence in $s$ can be assessed by the sample variance of $h_{1}, \ldots, h_{s}$. Using the central limit theorem, it is then possible to obtain estimates of $\pi_{j}$ with a desired precision (e.g. a 95\%-confidence interval) if one generates and analyzes a sufficiently large number of realizations.

To obtain a realization $h_{j}^{1}$ of $H_{j}$, we first draw $\mathrm{m}$ random numbers $\lambda^{1}, \ldots, \lambda^{m}$ from distrib utions $F^{1}, \ldots, F^{m}$. ${ }^{9}$ Throughout our analysis, we take $F^{j}$ to be a beta distribution with parameters $\left(\left(n_{j}+1\right) / 2,\left(n_{j}+1\right) / 2\right)$. This corresponds to the median of $n_{j}$ independently [0,1]-uniformly distributed voter ideal points, i. e. all individual voter positions are assumed to be distributed un iformly. ${ }^{10}$ Second, the realized constituency positions are sorted and the pivotal position $p$ is determined. Constituency $C_{p: m}$ is thus identified as the pivotal player of $\mathrm{E}$. It follows that $h_{1}^{j}=1$ for $j=p: m$, and 0 for all other constituencies.

The goal is to identify a simple rule for assigning voting weights to constituencies which if it exists - approximately satisfies equal representation conditions (1) or (2) for various num-

\footnotetext{
${ }^{9}$ We use a Java computer program. The source code is available upon request. Directly drawing the constituency medians $\lambda^{j}$ provides a huge computational advantage. Unfortunately, it prevents statements about the population median and, e.g., its average distance to the policy outcome.

${ }^{10}$ The mentioned asymptotic results for order statistics imply that only $F$ 's median position and density at the median matter when constituency sizes are large. So below findings are not specific to the assumption of uniform distributions at the bottom tier.
} 
bers of constituencies $m$ and population configurations $\left\{C_{1}, \ldots, C_{m}\right\}$. A natural focus is the investigation of power laws

$$
w_{j}=n_{j}^{\alpha}
$$

with $\alpha \in[0,1]$. For big $m$ this approximately includes Penrose's square root rule as the special case $\alpha=0.5$.

For any given $m$ and population configuration $\left\{C_{1}, \ldots, C_{m}\right\}$ under consideration, we fix $\alpha$ and then approximate $\pi_{j}$ by its empirical average $\hat{\mathrm{p}}_{j}$ in a run of 10 million iterations. This is repeated for different values of $\alpha$, ranging from 0 to 1 with a step size of 0.1 or 0.01 , in order to find the coefficient $\alpha$ which comes 'closest' to implying equal representation for the given configuration.

We have considered two different criteria in parallel for evaluating distance between the (estimated) probability vector $\hat{\mathrm{p}} \equiv\left(\hat{\mathrm{p}}_{1}, \ldots, \hat{\mathrm{p}}_{\mathrm{m}}\right)$ realized by weights $w$ and the ideal egalitarian vector $\pi^{*} \equiv\left(\sum_{k=1}^{m} n_{k}\right)^{-1} \cdot\left(n_{1}, \ldots, n_{m}\right)$. A first straightforward criterion is $\hat{\mathrm{p}}_{j}$ 's cumulative quadratic deviation from $\pi_{j}^{*}$,

$$
\sum_{j=1}^{m}\left(\hat{\pi}_{j}-\pi_{j}^{*}\right)^{2}
$$

which is equivalent to considering Euclidean distance between $\hat{\mathrm{p}}$ and $\pi^{*}$ in $\mathbf{R}^{m^{\mathbf{n}}}$. This a priori treats deviations from $\pi_{j}^{*}$ equally for all $j$, i. e. looks at deviations for constituencies as such rather than for individuals.

It seems, however, desirable in an egalitarian context to focus on the latter. So our second criterion considers cumulative quadratic deviations between the realized and the ideal chances of an individual. Any voter in any constituency $C_{j}$ would ideally determine the outcome with the same probability $1 / \sum_{k=1}^{m} n_{k}$, but vector $\hat{\mathrm{p}}$, actually gives him or her the probability $\hat{\mathrm{p}}_{j} / n_{j}$ of doing so. Treating all $n_{j}$ voters in any constituency $C_{j}$ equally then amounts to looking at

$$
\sum_{j=1}^{m} n_{j} \cdot\left(\frac{1}{\sum_{k=1}^{m} n_{k}}-\frac{\hat{\pi}_{j}}{n_{j}}\right)^{2}
$$


Minimization of (6) seems to us more relevant than that of (5). In any case optimal values of $\alpha$ are virtually unaffected by a switch between the two criteria. They are also almost unaffected by a switch from respective quadratic deviations to absolute deviations. So, with little loss of information, we will only present results for measure (6), referring to it as cumulative individual quadratic deviation below. Section 3.1 first investigates computer-generated random environments with constituency numbers between 10 and 100; we investigate several population configurations for each $m$ to check the robustness of an optimal $\alpha$. Sections 3.2 and 3.3 then briefly look at the EU Council of Ministers and the US Electoral College.

\subsection{Randomly generated configurations}

Table 1 reports the optimal values of $\alpha$ that were obtained for four sets of configurations $\left\{C_{1}, \ldots, C_{m}\right\} .{ }^{11}$ For $m \in\{10,15,20,25,30,40,50\}$, constituency sizes $n_{1}, \ldots, n_{m}$ were independently drawn from a uniform distribution over $\left[0.5 \cdot 10^{6}, 99.5 \cdot 10^{6}\right]$. Numbers in column (I) are the the optimal $\{0,0.1, \ldots, 0.9,1\} \subset[0,1]$, where probabilities $\hat{\mathrm{p}}_{j}$ were estimated by a simulation with 10 mio. iterations. Cumulative individual quadratic deviations for optimal $\alpha$ 's are shown in brackets. Column (II) reports the respective values obtained for an independent second set of constituency configurations; columns (III) and (IV) do likewise but based on the finer grid $\alpha \in\{0,0.01,0.02, \ldots, 0.99,1\} .^{12}$

While results for $m=10$ are still inconclusive, $\alpha \approx 0.5$ emerges as the very robust ideal coefficient for larger number of constituencies. The reported cumulative individual quadratic deviations are so small that even if the power laws assumed in (4) do not contain the theoretically best rule for equal representation in our median-voter context (because possibly constituencies' sizes are not the right reference point, but rather something like their PenroseBanzhaf or Shapley-Shubik index), they allow a sufficiently good approximation for most practical purposes.

Results in Table 1 are strongly suggesting that (an approximation of) Penrose's square root rule holds also in the context of median-voter based policy decisions in [0,1]. But optimality of $\alpha \approx 0.5$ could be an artifact of considering uniformly distributed constituency sizes $n_{1}, \ldots, n_{m}$,

\footnotetext{
${ }^{11}$ The configuration draws are independent across different values of $m$. Thus, the table actually reports optimal values obtained for 28 independent configurations.

${ }^{12}$ Hence columns (III) and (IV) each report on 101.7 simulation runs (with 10 mio. iterations each).
} 
which perhaps unrealistically makes small constituencies as likely as large ones. We therefore conduct similar investigations using other distributional assumptions.

\begin{tabular}{ccccc}
\hline \hline \# const & $(\mathbf{I})$ & $(\mathbf{I I})$ & $(\mathbf{I I I})$ & $\mathbf{( I V )}$ \\
\hline $\mathbf{1 0}$ & $\mathbf{0 . 5}$ & $\mathbf{0 . 6}$ & $\mathbf{0 . 3 9}$ & $\mathbf{0 . 0 0}$ \\
& $\left(1.22 \times 10^{-11}\right)$ & $\left(1.04 \times 10^{-11}\right)$ & $\left(2.20 \times 10^{-12}\right)$ & $\left(2.39 \times 10^{-11}\right)$ \\
$\mathbf{1 5}$ & $\mathbf{0 . 5}$ & $\mathbf{0 . 5}$ & $\mathbf{0 . 4 9}$ & $\mathbf{0 . 4 8}$ \\
$\mathbf{2 0}$ & $\left(1.43 \times 10^{-11}\right)$ & $\left(1.45 \times 10^{-13}\right)$ & $\left(2.79 \times 10^{-14}\right)$ & $\left(8.84 \times 10^{-14}\right)$ \\
& $\mathbf{0 . 5}$ & $\mathbf{0 . 5}$ & $\mathbf{0 . 4 9}$ & $\mathbf{0 . 4 9}$ \\
$\mathbf{2 5}$ & $\left(4.80 \times 10^{-14}\right)$ & $\left(8.59 \times 10^{-14}\right)$ & $\left(5.66 \times 10^{-15}\right)$ & $\left(6.91 \times 10^{-15}\right)$ \\
& $\mathbf{0 . 5}$ & $\mathbf{0 . 5}$ & $\mathbf{0 . 4 9}$ & $\mathbf{0 . 4 9}$ \\
$\mathbf{3 0}$ & $\left(9.25 \times 10^{-15}\right)$ & $\left(1.28 \times 10^{-14}\right)$ & $\left(5.37 \times 10^{-15}\right)$ & $\left(7.69 \times 10^{-15}\right)$ \\
& $\mathbf{0 . 5}$ & $\mathbf{0 . 5}$ & $\mathbf{0 . 4 9}$ & $\mathbf{0 . 4 9}$ \\
$\mathbf{4 0}$ & $\left(1.11 \times 10^{-15}\right)$ & $\left(5.12 \times 10^{-15}\right)$ & $\left(7.36 \times 10^{-15}\right)$ & $\left(2.38 \times 10^{-15}\right)$ \\
& $\mathbf{0 . 5}$ & $\mathbf{0 . 5}$ & $\mathbf{0 . 4 9}$ & $\mathbf{0 . 4 9}$ \\
$\mathbf{5 0}$ & $\left(3.38 \times 10^{-15}\right)$ & $\left(5.11 \times 10^{-15}\right)$ & $\left(3.69 \times 10^{-15}\right)$ & $\left(7.02 \times 10^{-15}\right)$ \\
& $\mathbf{0 . 5}$ & $\mathbf{0 . 5}$ & $\mathbf{0 . 5 0}$ & $\mathbf{0 . 5 0}$ \\
& $\left(3.06 \times 10^{-15}\right)$ & $\left(4.70 \times 10^{-15}\right)$ & $\left(3.10 \times 10^{-15}\right)$ & $\left(3.30 \times 10^{-15}\right)$ \\
\hline \hline
\end{tabular}

Table 1: Optimal value of $\alpha$ for uniformly distributed constituency sizes (cumulative individual squared deviations from ideal probabilities in parentheses)

Constituency sizes seem usually a matter of history, geography, or deliberate design. In the latter case, one might expect them to be clustered around some 'ideal' intermediate level. This makes a (truncated) normal distribution around some value $\bar{n}$ a focal assumption for constituency configurations. Table 2 indicates that, in this case, $\alpha=0.5$ is no longer the general clear winner from the considered set of parameters $\{0,0.1, \ldots, 0.9,1\}$. This is neither very surprising nor- from a square-root-rule point of view - very disturbing: Moderately many and more or less equally sized constituencies give rather little scope for discrimination between constituencies. Assigning slightly larger constituencies substantially more weight risks overshooting the mark, but assigning them only slightly more weight may not translate into an increased number of pivot positions at all. So, first, the optimal $\alpha$ can be expected to be rather sensitive to the precise constituency configuration at hand, especially when a small number of constituen- 
cies creates relatively few distinct opportunities to achieve a majority. And, second, in the wide range where extra weight to an above-the-average constituency translates into no or few extra winning coalitions, the objective function is very flat. This is nicely illustrated by Figure 1. Its minimization via Monte Carlo techniques is then particularly sensitive to remaining estimation errors. But note that the importance of these issues decreases as $m$ gets large. This indicates that applicability of the square root rule rests on enough flexibility regarding the formation of distinct winning coalitions.

\begin{tabular}{ccccc}
\hline \# const & $(\mathbf{I})$ & $(\mathbf{I I})$ & $($ III $)$ & $(\mathbf{I V})$ \\
\hline $\mathbf{1 0}$ & $\mathbf{0 . 0}$ & $\mathbf{0 . 0}$ & $\mathbf{0 . 0}$ & $\mathbf{0 . 0}$ \\
& $\left(1.22 \times 10^{-9}\right)$ & $\left(1.65 \times 10^{-9}\right)$ & $\left(9.21 \times 10^{-9}\right)$ & $\left(1.83 \times 10^{-9}\right)$ \\
$\mathbf{2 0}$ & $\mathbf{0 . 6}$ & $\mathbf{0 . 0}$ & $\mathbf{0 . 6}$ & $\mathbf{0 . 0}$ \\
$\mathbf{3 0}$ & $\left(2.19 \times 10^{-10}\right)$ & $\left(2.93 \times 10^{-10}\right)$ & $\left(2.82 \times 10^{-10}\right)$ & $\left(3.83 \times 10^{-10}\right)$ \\
& $\mathbf{0 . 1}$ & $\mathbf{0 . 2}$ & $\mathbf{0 . 4}$ & $\mathbf{0 . 5}$ \\
$\mathbf{4 0}$ & $\left(1.07 \times 10^{-10}\right)$ & $\left(1.07 \times 10^{-10}\right)$ & $\left(6.94 \times 10^{-11}\right)$ & $\left(6.76 \times 10^{-11}\right)$ \\
& $\mathbf{0 . 3}$ & $\mathbf{0 . 4}$ & $\mathbf{0 . 4}$ & $\mathbf{0 . 5}$ \\
$\mathbf{5 0}$ & $\left(1.72 \times 10^{-11}\right)$ & $\left(2.08 \times 10^{-11}\right)$ & $\left(2.32 \times 10^{-11}\right)$ & $\left(2.81 \times 10^{-13}\right)$ \\
& $\mathbf{0 . 4}$ & $\mathbf{0 . 2}$ & $\mathbf{0 . 3}$ & $\mathbf{0 . 3}$ \\
& $\left(1.60 \times 10^{-11}\right)$ & $\left(7.39 \times 10^{-12}\right)$ & $\left(3.56 \times 10^{-11}\right)$ & $\left(4.72 \times 10^{-11}\right)$ \\
& $\mathbf{0 . 5}$ & $\mathbf{0 . 5}$ & $\mathbf{0 . 5}$ & $\mathbf{0 . 5}$ \\
& $\left(1.01 \times 10^{-13}\right)$ & $\left(2.30 \times 10^{-12}\right)$ & $\left(1.99 \times 10^{-13}\right)$ & $\left(3.44 \times 10^{-13}\right)$ \\
\hline
\end{tabular}

Table 2: Optimal value of $\alpha$ for normally distributed constituency sizes $(\mu=1$ mio., $\sigma=200,000$; truncated below 0 ) 


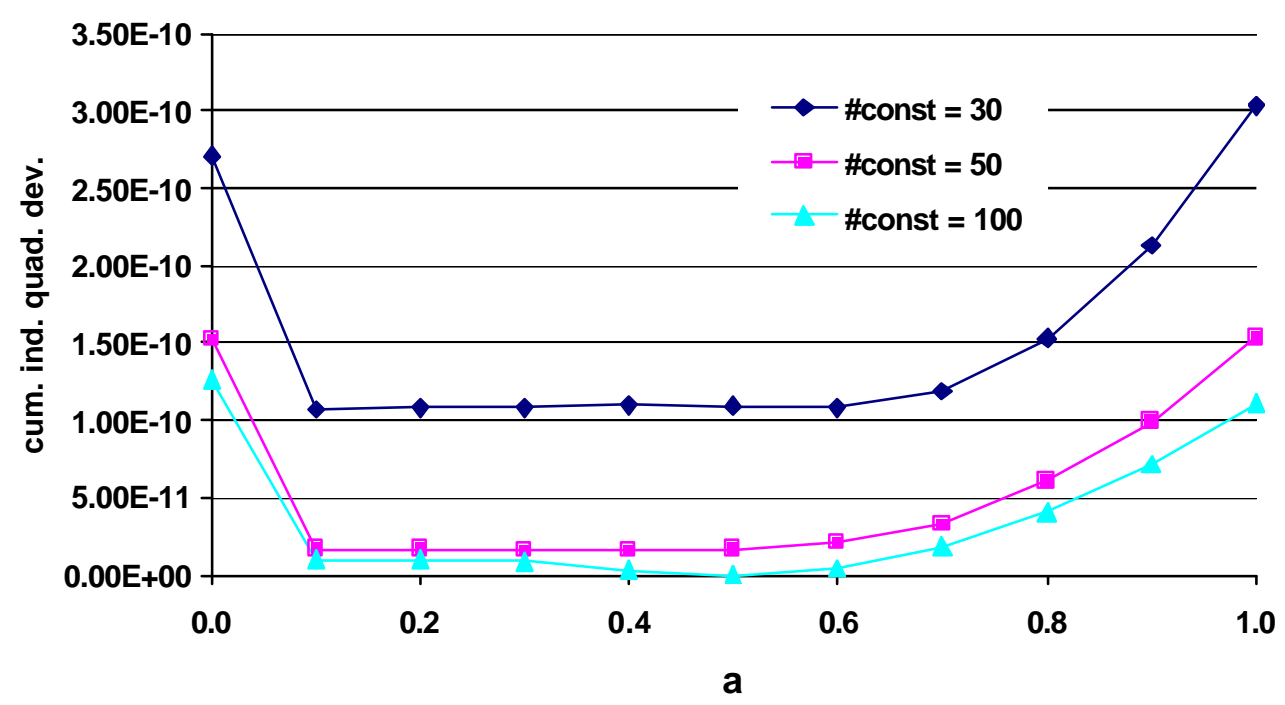

Figure 1: Cumulative individual quadratic deviation in normaldistribution runs (I) for different numbers of constituencies

When historical or geographical boundaries determine a population partition, a yet more natural distributional benchmark for $n_{j}$ is a power law such as Zipf's law (or zeta distribution), which has big empirical support in a variety of contexts. ${ }^{13}$ As an example, we consider the Pareto distribution with density function

$$
g(x \mid \kappa, \underline{x})=\kappa \frac{\underline{x}^{\kappa}}{x^{\kappa+1}}
$$

on $[\underline{x}, \infty)$. Parameter $\underline{x}$ provides a lower bound on $n_{j}$ and parameter $\kappa$ determines how quickly the probability of drawing a large (rather than small or medium-sized) constituency approaches 0 .

\footnotetext{
${ }^{13}$ Examples for which (approximative) power-law behavior has been observed include sizes of human settlements (Gabaix 1999, Reed 2004 ), the value of oil reserves in oil fields, the size of meteor impacts on the moon, or even frequencies of words in long sequences of text. Explanations for this widespread regularity are based on ideas such as self-organized criticality and highly optimized tolerance (see e. g. Newman 2000).
} 


\begin{tabular}{ccccccc}
\hline \hline & \multicolumn{5}{c}{ Number of constituencies } \\
\cline { 2 - 6 }$\kappa$ & $\mathbf{1 0}$ & $\mathbf{2 0}$ & $\mathbf{3 0}$ & $\mathbf{4 0}$ & $\mathbf{5 0}$ & $\mathbf{1 0 0}$ \\
\hline $\mathbf{1 . 0}$ & $\mathbf{0 . 5}$ & $\mathbf{0 . 5}$ & $\mathbf{0 . 5}$ & $\mathbf{0 . 5}$ & $\mathbf{0 . 5}$ & $\mathbf{0 . 5}$ \\
& $\left(1.32 \times 10^{-9}\right)$ & $\left(6.99 \times 10^{-11}\right)$ & $\left(1.32 \times 10^{-11}\right)$ & $\left(1.87 \times 10^{-11}\right)$ & $\left(1.31 \times 10^{-10}\right)$ & $\left(3.79 \times 10^{-12}\right)$ \\
$\mathbf{1 . 8}$ & $\mathbf{0 . 5}$ & $\mathbf{0 . 5}$ & $\mathbf{0 . 5}$ & $\mathbf{0 . 5}$ & $\mathbf{0 . 5}$ & $\mathbf{0 . 5}$ \\
& $\left(3.25 \times 10^{-9}\right)$ & $\left(4.78 \times 10^{-11}\right)$ & $\left(2.41 \times 10^{-11}\right)$ & $\left(2.25 \times 10^{-11}\right)$ & $\left(1.86 \times 10^{-11}\right)$ & $\left(1.04 \times 10^{-12}\right)$ \\
$\mathbf{3 . 4}$ & $\mathbf{0 . 0}$ & $\mathbf{0 . 5}$ & $\mathbf{0 . 5}$ & $\mathbf{0 . 5}$ & $\mathbf{0 . 5}$ & $\mathbf{0 . 5}$ \\
& $\left(3.72 \times 10^{-9}\right)$ & $\left(5.64 \times 10^{-11}\right)$ & $\left(2.41 \times 10^{-11}\right)$ & $\left(3.27 \times 10^{-12}\right)$ & $\left(2.67 \times 10^{-12}\right)$ & $\left(8.88 \times 10^{-13}\right)$ \\
$\mathbf{5 . 0}$ & $\mathbf{0 . 0}$ & $\mathbf{0 . 0}$ & $\mathbf{0 . 1}$ & $\mathbf{0 . 1 5}$ & $\mathbf{0 . 1}$ & $\mathbf{0 . 5}$ \\
& $\left(1.08 \times 10^{-8}\right)$ & $\left(3.61 \times 10^{-9}\right)$ & $\left(1.03 \times 10^{-10}\right)$ & $\left(2.85 \times 10^{-11}\right)$ & $\left(1.91 \times 10^{-10}\right)$ & $\left(7.54 \times 10^{-13}\right)$ \\
\hline \hline
\end{tabular}

Table 3: Optimal values of $\alpha$ for constituency sizes from Pareto distribution on $[0.1, \infty)$

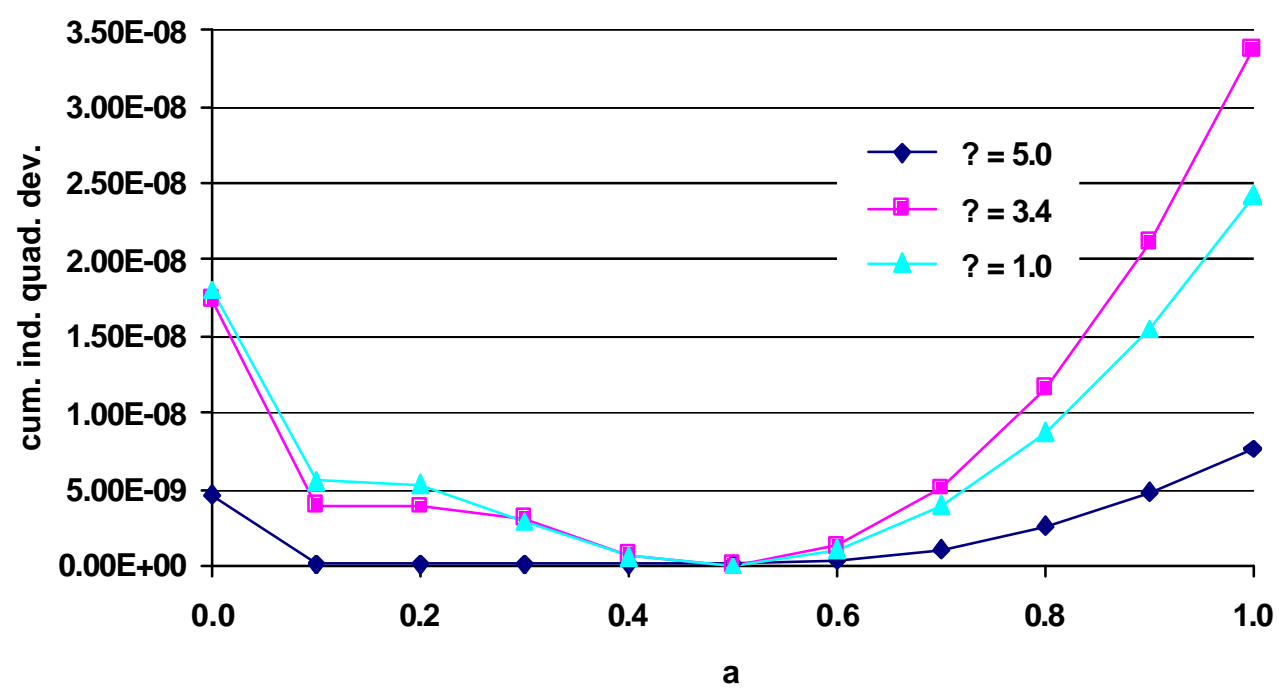

Figure 2: Cumulative individual quadratic deviation for $\mathrm{m}=30$ and different

Pareto distributions

Table 3 reports simulations with constituency sizes drawn from a Pareto distribution with $\underline{x}$ $=0.1$ and $\kappa \in\{1,1.8,3.4,5\}$, where numbers refer to million inhabitants. As long as the distri- 
bution is only moderately skewed (small $\kappa$ ), findings correspond nicely to those for the uniform distribution: $w_{j}=\sqrt{n_{j}}$ performs best and gets close to ensuring equal representation provided that the number of constituencies is sufficiently large. The former is no longer the case for a heavily skewed distribution of constituency sizes, i.e. when there are mostly small constituencies and only one or perhaps two large constituencies (reminiscent of atomic players in an otherwise oceanic game). Giving all constituencies equal weight does reasonably well. A coefficient $\alpha$ greater, but still not far from zero, improves on this by creating additional pivot positions for the large constituency. But for a moderate number of constituencies, increasing $\alpha$ after the initial introduction of asymmetry produces quite little effect (again, the objective function is rather flat over a big range as indicated by Figure 2) and then suddenly overshoots, resulting in too much power for the large constituency. For the same combinatorial reasons as in the normal-distribution case, this problem gets less severe, the greater is the total number of constituencies: For $m=100$ or larger, $\alpha=0.5$ turns out to be clearly optimal even for high skewness $(\kappa=5)$.

In summary, the above analysis of many different population configurations reveals three things. First, as Table 1 and Figures 1 and 2 show, $\alpha=0.5$ results in representation close to being as equal as possible for the given partition of the electorate. Second, for a moderately large number $m$ of constituencies $\alpha \approx 0.5$ is optimal in the considered class of power laws unless all constituency sizes are very similar (e.g., $n_{j}$ normally distributed with small variance) or rather similar with one or two outliers (corresponding to a heavily skewed distribution). Third, even in these extreme cases the optimal $\alpha$ converges to 0.5 as $m$ gets large. We now turn to two prominent real-world two-tier voting systems.

\subsection{EU Council of Ministers}

Together with Commission and Parliament, the Council of Ministers is one of the European Union's chief legislative bodies. It is widely held to be the most influential amongst the three and most voting power analysis concentrates on it. ${ }^{14}$ It consists of a national government repre-

\footnotetext{
${ }^{14}$ See Felsenthal and Machover (2004), Baldwin and Widgren (2004), and Leech (2002) for examples. Napel and Widgren (2006) argue formally that the Commission's and Parliament's positions are nearly irrelevant in the EU25 most common codecision procedure.
} 
sentative from each of the EU member states, endowed with voting weight that is (weakly) increasing in share of total population. ${ }^{15}$

Figure 3 illustrates the probabilities that representatives from differently sized member states are pivotal in the Council assuming a 50\% decision quota and assigning voting weight based on populations size via $w_{j}=n_{j}^{\alpha} \cdot{ }^{16}$ In line with above findings for randomly generated two-tier voting systems, $\alpha=0.5$ performs best amongst all coefficients in $\{0,0.1, \ldots, 1\}$. The figure shows how close the implied probability of country $j$ being pivotal comes to the respective ideal value, which would implement a priori perfectly equal representation. Only the most populous country, Germany, would be visibly misrepresented (here: over-represented).

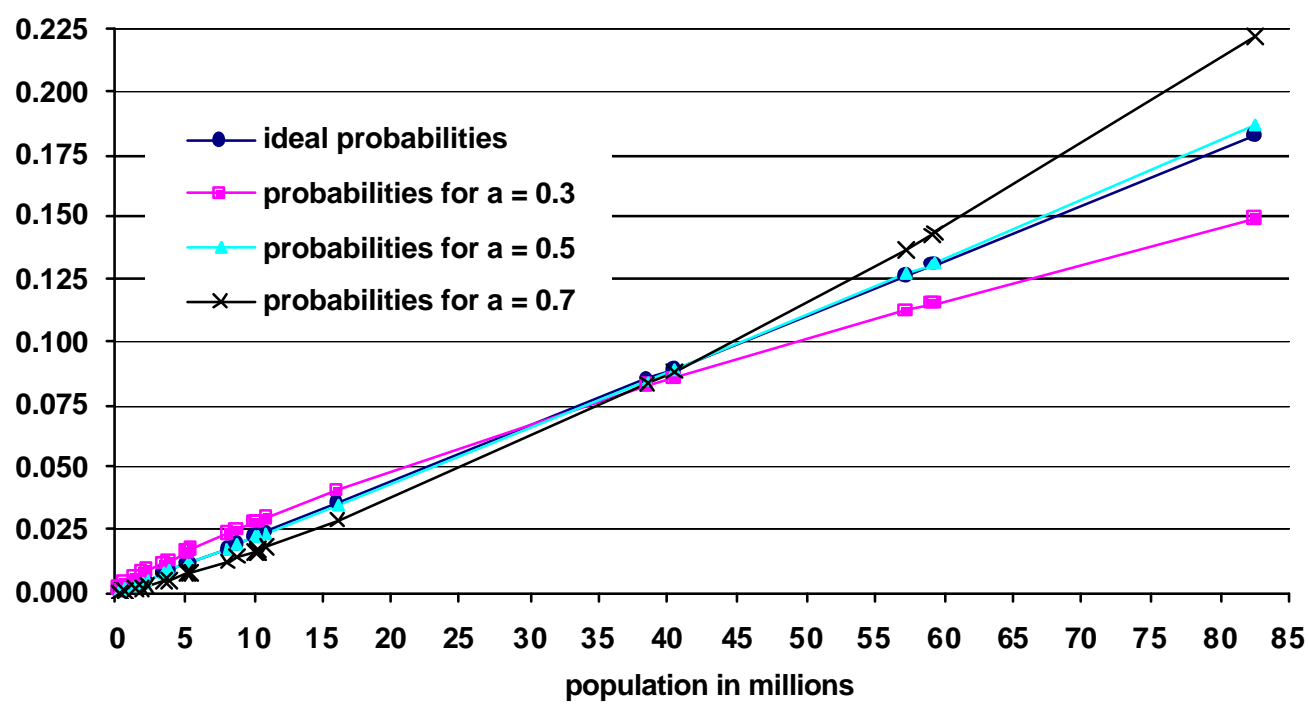

Figure 3: EU25 with weights $w_{j}=n_{j}^{\alpha}$ compared to ideal probabilities

With the exceptions of Germany, Spain and Poland, the current Council weights agreed in the Treaty of Nice correspond roughly to the square root of populations. It follows that if a single quota of $50 \%$ were used in the Council of Ministers, probabilities $\hat{\mathrm{p}}_{j}$ would be close to their egalitarian values (with the mentioned exceptions). However, the Council uses a qualified

\footnotetext{
${ }^{15}$ The current voting rule is actually quite complex. In addition to standard weighted voting it involves the requirement that the majority weight supporting a policy represents a simple majority of member states and $62 \%$ of population.
} 
majority of $72.2 \%$ of the weight plus additional population and number-of-supporters requirements. The latter have little effect (see Felsenthal and Machover 2001) but the former makes a real difference.

Comparison of Figures 4 and 5 illustrates this. With a quota significantly above 50\%, a priori greater centrality of median opinion in large countries such as Germany or France no longer provides greater chances of being pivotal in the Council. It actually reduces them. So under the qualified majority rule representation is not only even more biased against German voters, but now also French, British, and Italian representatives are less often pivotal than would be nece ssary to give all voters in the EU equal representation in the Council.
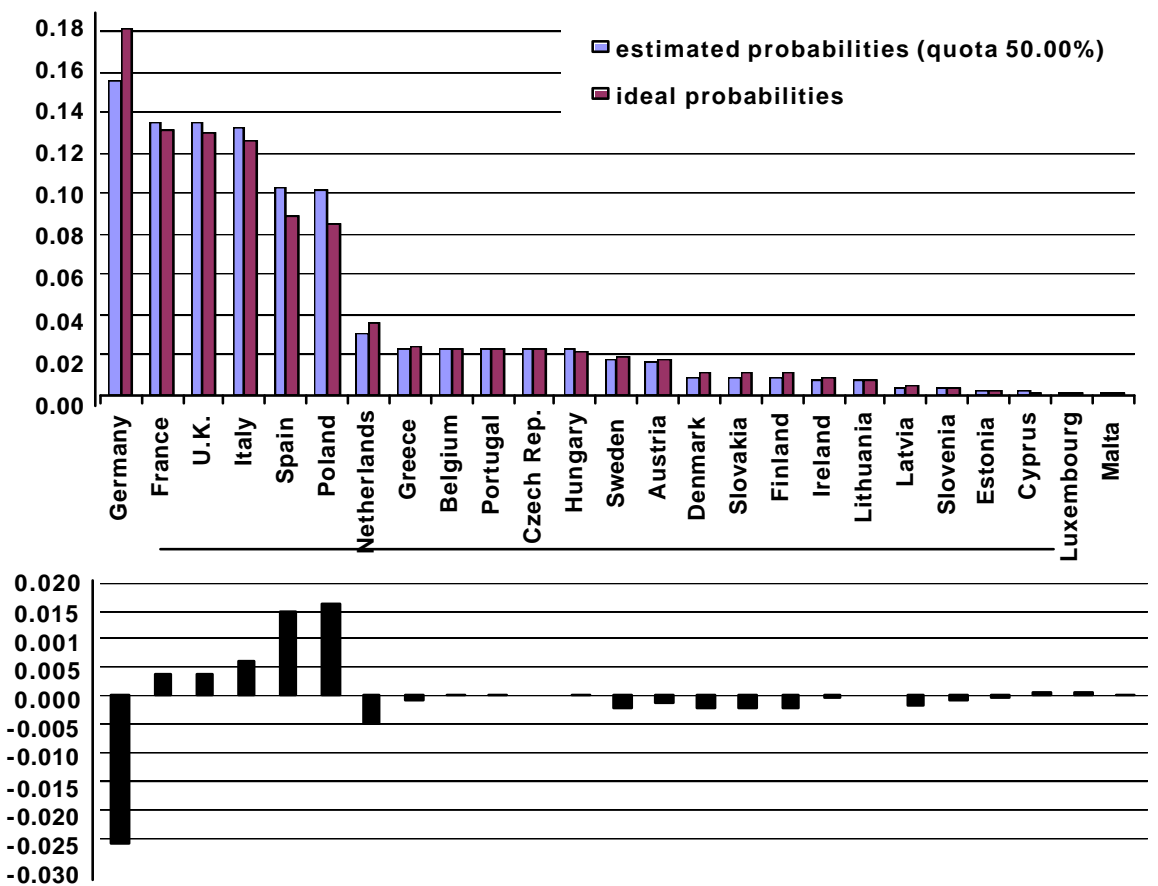

Figure 4: EU25 with Nice weights and hypothetical quota of 50\%

\footnotetext{
${ }^{16}$ These and the following numbers are Monte-Carlo estimates obtained from six runs with 10 million iterations each. In case of qualified majority voting, the pivot is identified by assuming a status quo $q=0 \in X$.
} 

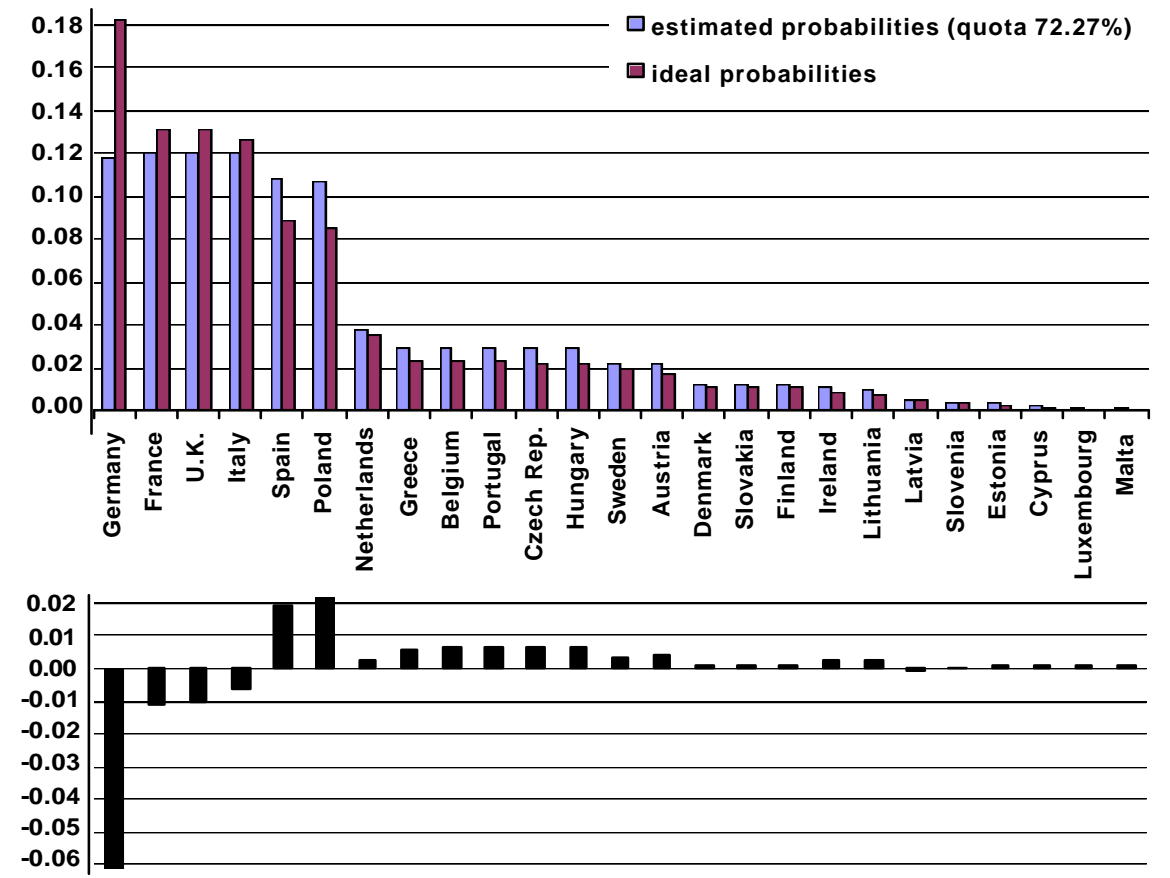

Figure 5: EU25 with Nice weights and 72.2\% single quota

Note that this analysis not only puts historical voting patterns and preference similarities between some members behind a veil of ignorance but also, as do the mentioned applied studies, it disregards differences between the bottom-tier voting procedures which determine national governments. For example, the UK uses plurality rule or a "first-past-the-post" system, whilst Germany uses a roughly proportional system. ${ }^{17}$ This difference might have a systematic effect on the respective accuracy of our median voter assumption at the constituency level. To the extent that it does not, our findings are robust.

Investigation of a quota variation even for a very idealized Council illustrates that the decision threshold is not only affecting the balance of 'external costs' and 'decision-making costs' (Buchanan and Tullock 1962) or challenging the so-called 'efficiency' of a decision-making body (operationalized as the probability that a random proposal is passed in the classical 0-1 setting by Felsenthal and Machover 2001 and Baldwin et al. 2001 amongst others). The quota

\footnotetext{
${ }^{17}$ Germany's system is actually complex: some members of parliament are directly elected in a firstpast-thepost manner, others get seats in proportion to their party's vote. Stratmann and Baur (2002) use this distinction amongst German parliamentarians to show that different electoral procedures indeed translate into different policies.
} 
also has important implications for equality of representation and hence the legitimacy of decisions.

\subsection{US Electoral College}

US citizens elect their president via an Electoral College. The 50 states and Washington DC each send representatives to it. Their number is weakly increasing in the represented share of total population. Although most Electors are not legally bound to vote in any particular way, all state representatives cast their vote for the presidential candidate who secured a plurality of the respective state's popular vote with only minor exceptions. The US Electoral College is therefore commonly treated as a weighted voting system. It actually inspired the important development of the generating function approach (see Mann and Shapley 1962 and recently Algaba et al. 2003), which is the main computational technique for evaluating power under weighted voting in binary settings. Large numbers of players could hitherto only be tackled by the Monte Carlo method (see Mann and Shapley 1960).

Decisions in the Electoral College have in the recent past been essentially binary. The pivotal player amongst the states' median voters might, however, feature prominently in a more sophisticated model of how the two main contestants are selected. In any case, consideration of strategic policy choices in a convex space provides a useful benchmark for the preference-free dichotomous model considered by Penrose (1946) and, specifically addressing the Electoral College, Banzhaf (1968). ${ }^{18}$

\footnotetext{
${ }^{18}$ Early weighted voting analysis of US presidential elections also includes Brams (1978, ch. 3).
} 


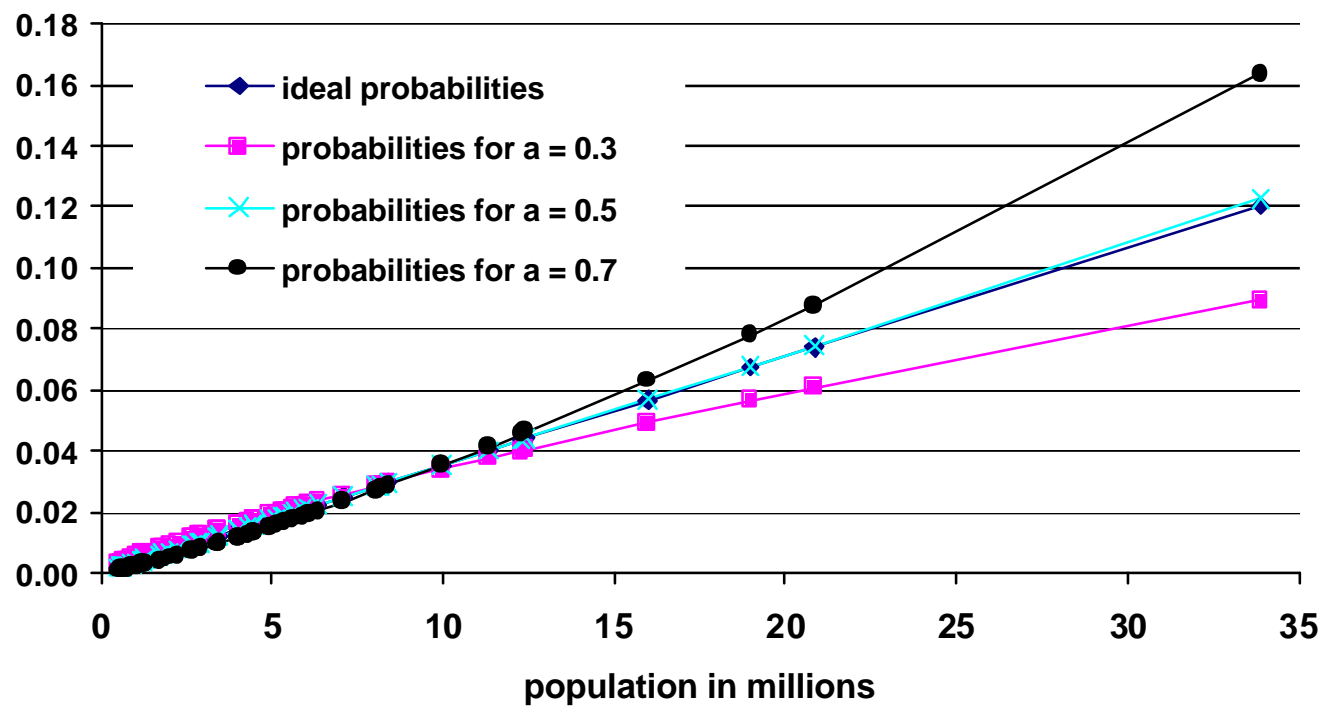

Figure 6: US Electoral College with weights $w_{j}=n_{j}^{\alpha}$ compared to ideal probabilities

Figure 6 illustrates the result of determining (hypothetical) weights for state representatives based on current US state population data. Corroborating the findings of Penrose and Banzhaf, the square root rule corresponding to $\alpha=0.5$ is again extremely successful in ensuring equal representation. Moreover, as shown by Figure 7, it is clearly the best amongst all considered rules.

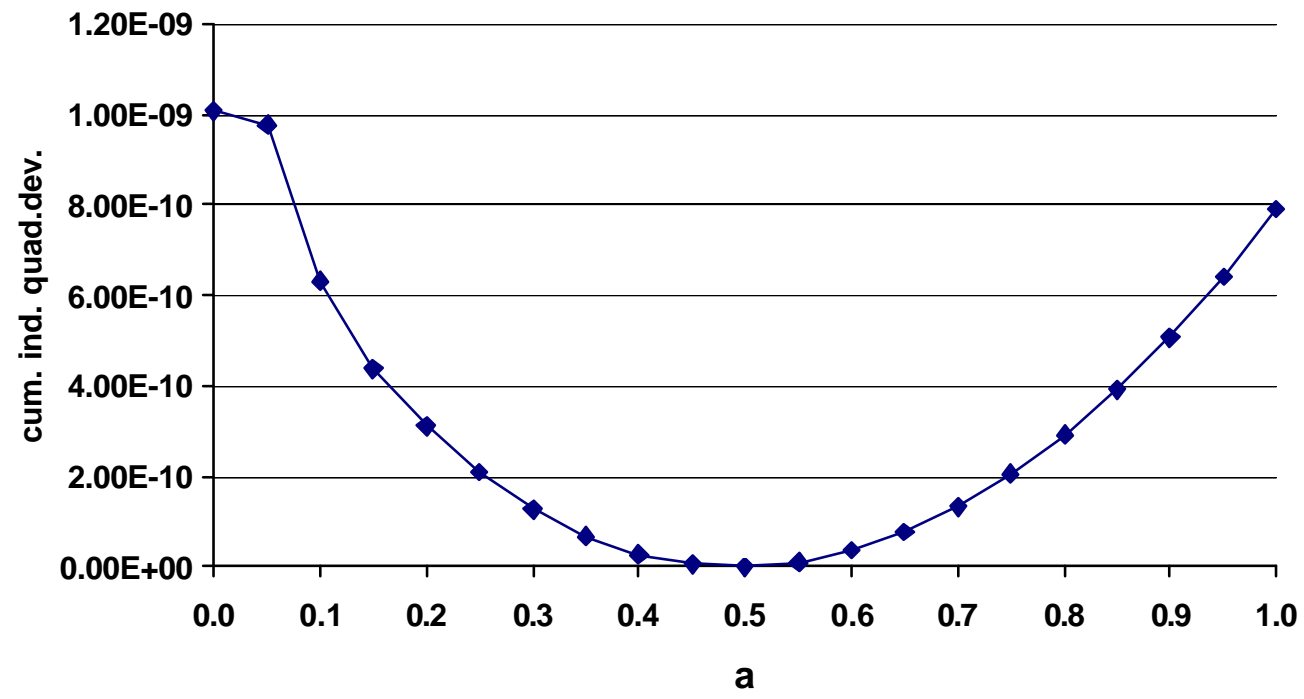

Figure 7: Cumulative individual quadratic deviation for US Electoral College 


\section{Concluding remarks}

As highlighted, e.g., by Good and Mayer (1975) and Chamberlain and Rothschild (1981), even slight changes regarding decision making at the individual or collective level can produce very different recommendations for operationalizing the one-person, one-vote principle, interpreted here as identical (and positive) indirect expected influence on final outcomes by all voters. Apart from our 'veil of ignorance' perspective with a priori identical but independent voters, the setting considered in this paper is very remote from the preference-free binary model considered by Penrose $(1946)$, Banzhaf $(1965,1968)$ and others. It is thus surprising that voting weight proportional to square root of population, which corresponds to Penrose's original suggestion for most practical purposes, ${ }^{19}$ emerges as optimal for both prominent real-world examples as well as numerous artificial population configurations.

This result matters not only from an abstract point of view. It shows that numerous applied studies have indeed used a robust benchmark. This is also highlighted by recent work of Beisbart and Bovens (2005), which discovers optimality of the square root rule in a very different binary, utility-based egalitarian model. And at least for large constituency populations consisting of many small blocks, Barberà and Jackson (2005) produce similar conclusions in an entirely utilitarian framework..$^{20}$ In summary, the square root rule is a simple and trustworthy norm, not an artifact of a particular objective function or setting. This insight can hopefully increase its effect on constitutional design in the real world. ${ }^{21}$

We see several promising directions for future research. First, it is desirable to obtain an alytical results at least for some special cases. At a level unfortunately still hidden to us, the central limit theorem and approximate proportionality of square root of population and standard deviation of the respective median position seem to be the ultimate source of above observations.

\footnotetext{
${ }^{19}$ In fact, Penrose (1946) seems to have deliberately blurred the distinction between voting weight and voting power in his discussion of equal representation in a world assembly.

${ }^{20}$ Also see Beisbart et al. (2005) for a related utilitarian investigation.

${ }^{21}$ The square root rule already played a significant role in the public discussion of a possible EU Constitution. See, for example, the open letter by Bilbao et al. (2004) to the EU members' governments with repercussions in various national news outlets.
} 
Second, the effects of changing the top-tier decision quota deserve attention in particular in the context of the European Union. Our preliminary investigations indicate that optimality of $\alpha=0.5$ remains unaffected by small increases of the top-tier quota. Of course, even approx imately equal representation is impossible under unanimity rule (keeping the bottom -tier role of the median). In between, optimal assignments tend to give large constituencies greater weight than implied by $\alpha=0.5$.

Third, it is likely that also in our setting some combinatorial index of voting power, rather than voting weight, would be the best reference point for proportionality to square root of population. Standard indices (e. g., Penrose-Banzhaf or Shapley -Shubik index) can, however, be ruled out because they implicitly assume identical stochastic behavior of top-tier voters, from which a simple linear rule involving the Shapley -Shubik index would follow. There conceiv ably exist many other candidates. Finding a suitable index would be useful for small constituency numbers. Given the close-to-equal representation obtained above already for as few as 15 constituencies, this seems no priority though.

\section{References}

Algaba, E., J. M. Bilbao, J. R. F. García, and J. J. López (2003). Computing power indices in weighted multiple majority games. Mathematical Social Sciences 46, 63-80.

Ansolabehere, S., A. Gerber, and J. Snyder (2002). Equal votes, equal money: Court-ordered redistricting and the distribution of public expenditures in the American States. American Political Science Review 96(4), 767-777.

Arnold, B. C., N. Balakrishnan, and H. N. Nagaraja (1992). A First Course in Order Statistics. New York: John Wiley \& Sons.

Baldwin, R. and M. Widgrén (2004). Council voting in the Constitutional Treaty: Devil in the details. Policy Brief 53, Centre for European Policy Studies.

Baldwin, R. E., E. Berglöf, F. Giavazzi, and M. Widgrén (2001). Nice Try: Should the Treaty of Nice Be Ratified? Monitoring European Integration 11. London: Center for Economic Policy Research. 
Balinski, M. L. and H. P. Young (2001). Fair Representation-Meeting the Ideal of One Man, One Vote (Second ed.). Washington, D.C.: Brookings Institution Press.

Banks, J. S. and J. Duggan (2000). A bargaining model of social choice. American Political Science Review 94(1), 73-88.

Banzhaf, J. F. (1965). Weighted voting doesn't work: A mathematical analysis. Rutgers Law Review 19(2), 317-343.

Banzhaf, J. F. (1968). One man, 3.312 votes: A mathematical analysis of the Electoral College. Villanova Law Review 13, 304-332.

Barberà, S. and M. O. Jackson (2005). On the weights of nations: Assigning voting weights in a heterogeneous union. mimeo, CODE, Universitat Autonoma de Barcelona and California Institute of Technology.

Beisbart, C. and L. Bovens (2005). Why degressive proportionality? An argument from cartel formation. mimeo, University of Dortmund and London School of Economics.

Beisbart, C., L. Bovens, and S. Hartmann (2005). A utilitarian assessment of alternative decision rules in the Council of Ministers. European Union Politics 6(4), 395-419.

Bilbao, J. M., F. Bobay, W. Kirsch, M. Machover, I. McLean, B. Plechanovová, F. Pukelsheim, W. Slomczynski, K.Zyczkowski, and many others. (2004). Letter to the governments of the EU member states. URL (consulted last in August 2005): http://silly.if.uj.edu.pl/ karol/pdf/OpenLetter.pdf.

Brams, S. J. (1978). The Presidential Election Game. New Haven, CT: Yale University Press.

Buchanan, J. M. and G. Tullock (1962). The Calculus of Consent. Ann Arbor, MI: University of Michigan Press.

Chamberlain, G. and M. Rothschild (1981). A note on the probability of casting a decisive vote. Journal of Economic Theory 25, 152-162.

Epstein, D. and S. O'Halloran (1999). Measuring the electoral and policy impact of majorityminority voting districts. American Journal of Political Science 43(2), 367-395.

Feix, M. R., D. Lepelley, V. Merlin, J.-L. Rouet, and L. Vidu (2005). Majority efficient representation of the citizens in a federal union. mimeo, Université de la Réunion, Université de Caen, and Université d'Orleans. 
Felsenthal, D. and M. Machover (1998). The Measurement of Voting Power - Theory and Practice, Problems and Paradoxes. Cheltenham: Edward Elgar.

Felsenthal, D. and M. Machover (2001). The Treaty of Nice and qualified majority voting. Social Choice and Welfare 18(3), 431-464.

Felsenthal, D. and M. Machover (2004). Analysis of QM rules in the draft Constitution for Europe proposed by the European Convention. Social Choice and Welfare 23, 1-20.

Gabaix, X. (1999). Zipf's law for cities: An explanation. Quarterly Journal of Economics 114, 739-767.

Gelman, A., J. N. Katz, and J. Bafumi (2004). Standard voting power indexes don't work: An empirical analysis. British Journal of Political Science 34(1133), 657-674.

Gelman, A., J. N. Katz, and F. Tuerlinckx (2002). The mathematics and statistics of voting power. Statistical Science 17, 420-435.

Good, I. and L. S. Mayer (1975). Estimating the effic acy of a vote. Behavioral Science 20, 2533.

Horiuchi, Y. and J. Saito (2003). Reapportionmente and redistribution: Consequences of electoral reform in Japan. American Journal of Political Science 47(4), 669-682.

Laruelle, A., R. Martínez, and F. Valenciano (2006). Success versus decisiveness: Conceptual discussion and case study. Journal of Theoretical Politics (forthcoming).

Leech, D. (2002). Designing the voting system for the EU Council of Ministers. Public Choice 113(3-4), 437-464.

Leech, D. (2003). Power indices as an aid to institutional design: The generalised apportio nment problem. In M. J. Holler, H. Kliemt, D. Schmidtchen, and M. Streit (Eds.), Yearbook on New Political Economy, Volume 22. Tübingen: Mohr Siebeck.

Lindner, I. and M. Machover (2004). L.S. Penrose's limit theorem: Proof of some special cases. Mathematical Social Sciences 47, 37-49.

Mann, I. and L. S. Shapley (1960). Values of large games, IV: Evaluating the Electoral College by Monte Carlo techniques. Memorandum RM-2651, The Rand Coporation.

Mann, I. and L. S. Shapley (1962). Values of large games, VI: Evaluating the Electoral College exactly. Memorandum RM-3158-PR, The Rand Corporation. 
Metropolis, N. and S. Ulam (1949). The Monte Carlo method. Journal of the American Statistical Association 44, 335-341.

Napel, S. and M. Widgrén (2006). The inter-institutional distribution of power in EU codecision. Social Choice and Welfare (forthcoming).

Newman, N. (2000). The power of design. Nature 405, 412-413.

Penrose, L. S. (1946). The elementary statistics of majority voting. Journal of the Royal Statistical Society 109, 53-57.

Reed, W. J. (2004). On the rank-size distribution for human settlements. Journal of Regional Science 42, 1-17.

Shapley, L. S. and M. Shubik (1954). A method for evaluating the distribution of power in a committee system. American Political Science Review 48(3), 787-792.

Stratmann, T. and M. Baur (2002). Plurality rule, proportional representation, and the German Bundestag: How incentives to pork-barrel differ across electoral systems. American Journal of Political Science 46(3), 506-514.

Taylor, A. D. and W. S. Zwicker (1999). Simple Games. Princeton, NJ: Princeton University Press. 


\section{CSGR Working Paper S eries}

160/05, May

161/05, May

162/05, May

163/05, May

164/05, May

165/05, May

166/05, May

167/05, May

168/05, May

169/05, May

170/05, May

171/05, August

172/05, August

173/05, August

174/05 September
R Cohen

The free movement of money and people: debates before and after ' $9 / 11$ '

E Tsingou

Global governance and transnational financial crime: opportunities and tensions in the global anti-money laundering regime

S. Zahed

'Iranian National Identity in the Context of Globalization: dialogue or resistance?'

E. Bielsa

'Globalisation as Translation: An Approximation to the Key but Invisible Role of Translation in Globalisation'

J. Faundez

'The rule of law enterprise - towards a dialogue between practitioners and academics'

M. Perkmann

'The construction of new scales: a framework and case study of the EUREGIO crossborder region'

M. Perkmann

'Cross-border co-operation as policy entrepreneurship: explaining the variable success of European cross-border regions'

G. Morgan

'Transnational Actors, Transnational Institutions, Transnational spaces: The role of law firms in the internationalisation of competition regulation'

G. Morgan, A. Sturdy and S. Quack

'The Globalization of Management Consultancy Firms: Constraints and Limitations'

G. Morgan and S. Quack

'Institutional legacies and firm dynamics: The growth and internationalisation of British and German law firms'

C Hoskyns and S Rai

'Gendering International Political Economy'

James Brassett

'Globalising Pragmatism'

Jiro Yamaguchi

'The Politics of Risk Allocation Why is Socialization of Risks Difficult in a Risk Society?'

M. A. Mohamed Salih

'Globalized Party-based Democracy and Africa: The Influence of Global Party-based Democracy Networks'

Mark Beeson and Stephen Bell

The G20 and the Politics of International Financial Sector Reform: Robust Regimes or Hegemonic Instability? 


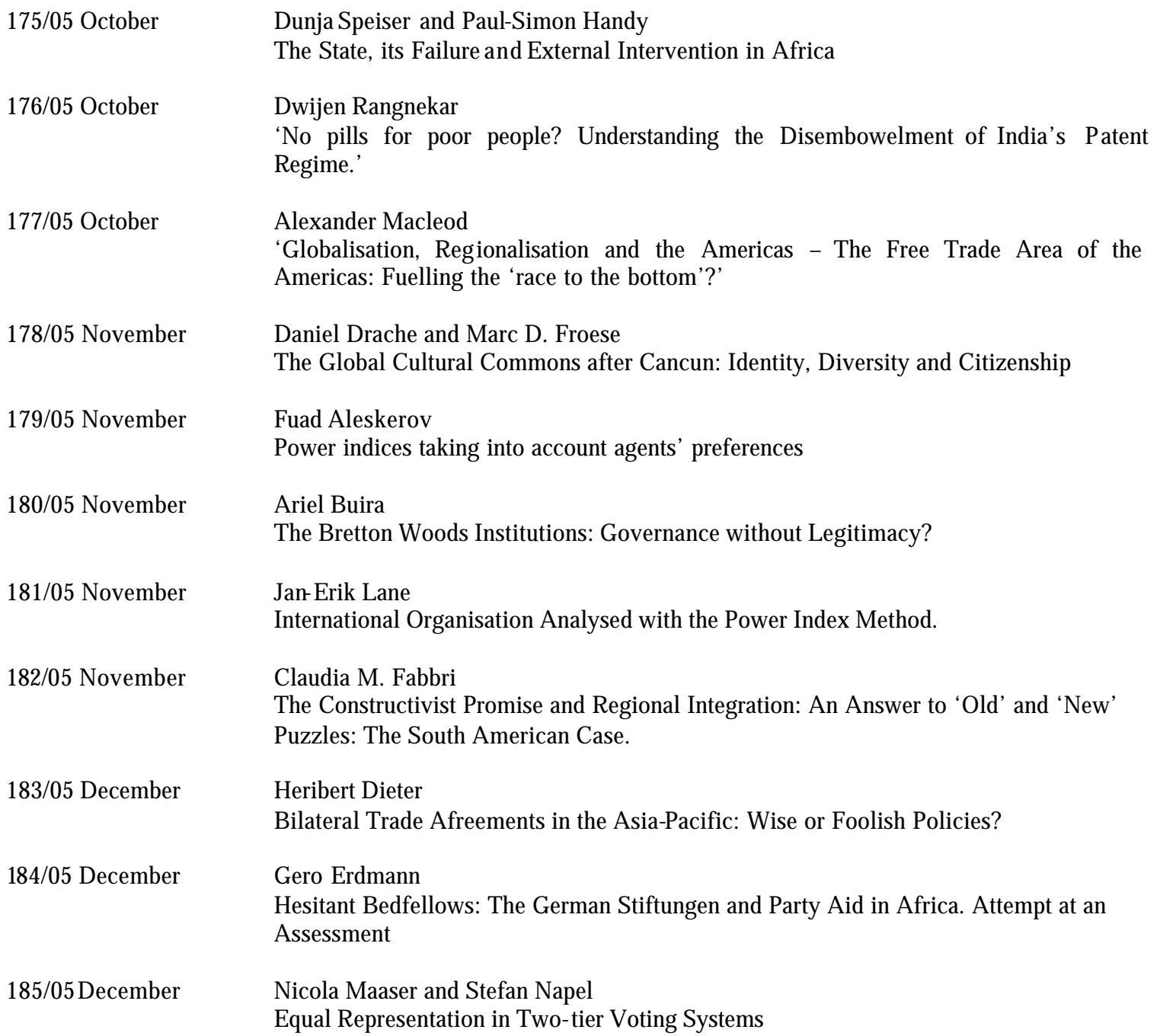

185/05 December

Dunja Speiser and Paul-Simon Handy

The State, its Failure and External Intervention in Africa

Dwijen Rangnekar

'No pills for poor people? Understanding the Disembowelment of India's Patent Regime.'

Alexander Macleod

'Globalisation, Regionalisation and the Americas - The Free Trade Area of the Americas: Fuelling the 'race to the bottom'?'

Daniel Drache and Marc D. Froese

The Global Cultural Commons after Cancun: Identity, Diversity and Citizenship

Fuad Aleskerov

Power indices taking into account agents' preferences

Ariel Buira

The Bretton Woods Institutions: Governance without Legitimacy?

Jan-Erik Lane

International Organisation Analysed with the Power Index Method.

Claudia M. Fabbri

The Constructivist Promise and Regional Integration: An Answer to 'Old' and 'New'

Puzzles: The South American Case.

Heribert Dieter

Bilateral Trade Afreements in the Asia-Pacific: Wise or Foolish Policies?

Gero Erdmann

Hesitant Bedfellows: The German Stiftungen and Party Aid in Africa. Attempt at an Assessment

Nicola Maaser and Stefan Napel

Equal Representation in Two-tier Voting Systems

\section{Centre for the Study of Globalisation and Regionalisation}

University of Warwick

Coventry CV4 7AL, UK

Tel: $+44(0) 2476572533$

Fax: +44 (0)24 76572548

Email: csgr@warwick.ac.uk

Web address: http://www.csgr.org 